\title{
Use of Black Gram Polysaccharide Mucilage as Release Retardant in the Development of Sustained Release Matrix Pellets of Ciprofloxacin Hydrochloride
}

\author{
Ige Pradum Pundlikrao*, Gadgil Prajakta Pradip, Sonawane Raju Onkar \\ Department of Pharmaceutics, R C Patel Institute of Pharmaceutical Education and Research Shirpur, Dhule, Maharashtra 425405, \\ INDIA.
}

\begin{abstract}
Ciprofloxacin $\mathrm{HCl}$ is a BCS class III drug with high solubility and low permeability. It is a second generation fluoroquinolone antibiotic used in the treatment of mild to moderate urinary and respiratory tract infections. It has half-life of 4-5 h and bioavailability about $70 \%$. The main objective of this research work was to develop sustained release matrix pellets of ciprofloxacin $\mathrm{HCl}$ to obtained better delivery of ciprofloxacin $\mathrm{HCl}$ to the stomach and the proximal parts of the small intestine by increasing the mean residence time (MRT) in the stomach using novel natural excipient that is black gram polysaccharide as release retarding polymer. The pellets were prepared by an extruder spheronizer. The characterization of pellets was done using X-ray powder diffraction (XRPD), Scanning electron microscopy (SEM), flow properties, percent friability, drug content, percent production yield, swelling ability of pellets, mucoadhesive strength, and in-vitro drug release and stability studies. The optimized pellets were found to be free flowing and had yield $30.4 \%$ and drug content $97.79 \pm 0.60 \%$. The optimized formulation NF1 showed sustained drug release of $96.08 \%$ up to $12 \mathrm{~h}$. The optimized formulation (NF1) showed good flow properties which were within the official limits. The optimized formulation showed percent mucoadhesion of $72 \%$ in $0.1 \mathrm{~N} \mathrm{HCL}(\mathrm{pH} 1.2)$. It can be concluded that black gram polysaccharide mucilage can be effectively used as release retarding excipient in sustained release formulations.
\end{abstract}

Key words: Sustained release drug delivery system, Ethyl cellulose, Black gram polysaccharide, Pelletization, in vitro drug release study.

\section{INTRODUCTION}

Oral sustained drug delivery system is useful if a drug is well-absorbed throughout the entire gastrointestinal tract. However, some drugs tend to be absorbed only in the stomach or upper part of the small intestines, mainly because of a narrow absorption window. The delivery site has to be controlled in order to control absorption. ${ }^{1}$ Physiological factors such as gastrointestinal transit time, regional $\mathrm{pH}$, surface area, enzymatic activity and colonic microflora influence drug absorption; some of these factors may be used to achieve control over drug absorption. ${ }^{2}$ Gastro retentive drug delivery system is controlled drug delivery system with prolonged residence time in the stomach is of particular interest for drugs that are locally active in the stomach, have an absorption window in the stomach or in the upper small intestine and unstable in the intestinal or colonic environment. As the total gastro intestinal transit time of the dosage form is increased by prolonging the gastric residence time, these systems can also be used as extended release devices with a reduced frequency of administration and, thus, improved patient compliance. ${ }^{3,4}$ This type of drug delivery system will have relatively less side effect and removes the need of repeated dosages. ${ }^{5}$
Submission Date: 10-09-2017; Revision Date: 08-11-2017; Accepted Date: 15-11-2017

DOI: 10.5530/ijper.52.3.45 Correspondence: Dr. Ige Pradum Pundlikrao, Associate Professor, Department of Pharmaceutics, R. C. Patel Institute of Pharmaceutical Education and Research, Karwandnaka, Shirpur, Dhule, Maharashtra, 425405, INDIA.

Phone: +91-2563-255189

E-mail: pradyumna_1978@ rediffmail.com

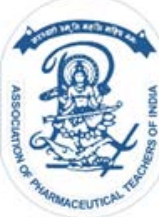

www.ijper.org 
Matrix pellets are one of the most popular multiparticulate dosage forms. Pelletization is an agglomeration process that converts fine powders or granules of bulk drugs and excipients into small, free-flowing, spherical or semi spherical units, referred to as pellet. ${ }^{6,7}$ Pellets as drug delivery system offer not only therapeutic advantages, such as less irritation of the gastro-intestinal tract and lowered risk of side effects due to dose dumping, but also technological advantages, for example, better flow properties, less friable dosage form, narrow particle size distribution, ease of coating and uniform packing. Pellets are commonly filled into hard gelatine capsules but can also be compressed to tablets. ${ }^{8}$

Ciprofloxacin $\mathrm{HCl}$ is broad-spectrum fluoroquinolone antibacterial agent and absorbed from the stomach and the proximal part of the small intestine with oral bioavailability of about $70 \%$ and $4-5$ h half-life. It is used in treatment of complicated and uncomplicated urinary tract infections (UTIs). It is the most active quinolone against Pseudomonas Aeruginosa. The mechanism involved is the inhibition of DNA gyrase enzyme which is an essential component of bacterial DNA replication. ${ }^{9-13}$

Black gram polysaccharide is naturally occurring polysaccharide contains proteins, D-galactose, L-rhamnose, galacturonic acid, L-arabinose which is isolated from black gram seeds. ${ }^{14}$ There are various sustained release polymers available which includes hydroxyl propyl methyl cellulose (HPMC), ethyl cellulose, polyethylene oxide and chitosan.

The basic rationale behind sustained/controlled drug delivery is to alter the pharmacokinetics and pharmacodynamics of pharmacologically active substances by using novel drug delivery systems or by modifying the molecular structure and/or physiological parameters inherent in a selected route of administration. ${ }^{15-23}$

The main objective of the present work was to prepare sustained release matrix pellets using a novel excipient (black gram polysaccharide) by extrusion-spheronization so as to extend the residence time of the drug in the stomach. The prepared pellets were characterised by flow properties, mucoadhesive strength, SEM, in vitro drug release. Novelty of this work is that, the matrix pellets of Ciprofloxacin $\mathrm{HCl}$ using black gram polysaccharide as release retarding material has not been reported.

\section{MATERIALS AND METHODS}

Black gram seeds were purchased from the local market, Shirpur, Ciprofloxacin $\mathrm{HCl}$ was obtained as gift sample from Cipla Ltd, Mumbai. Ethyl cellulose, MCC, PVPK30 was obtained as a gift sample from Colorcon Asia Pvt. Ltd. Goa, India. Isopropyl alcohol was obtained from S.D Fine Chemicals. All the reagents used were of analytical grade.

\section{Isolation of Black Gram Polysaccharide Mucilage}

$250 \mathrm{~g}$ of Black gram seeds were taken and ground into a powder in a grinder. $20 \mathrm{~g}$ of this powder was taken in $1000 \mathrm{~mL}$ beaker containing $800 \mathrm{~mL}$ of water and the slurry was prepared. This slurry was boiled at a temperature below $60^{\circ} \mathrm{C}$ for $2 \mathrm{~h}$ under stirring condition. The viscous solution was kept overnight for the release of polysaccharides into water and squeezed in a muslin cloth to obtained the filtrate. To this filtrate equal amount of acetone was added to precipitate the polysaccharides. The polysaccharides were separated by filtration method, dried, powdered and stored at room temperature in air tight container. ${ }^{30}$

\section{Characterization of Black Gram Polysaccharide Mucilage}

To confirm the presence of polysaccharide Ruthenium red test, Molisch's test and Iodine test were performed.

Molisch's test- To the mucilage powder alcoholic $1 \mathrm{~mL}$ solution of $\alpha$-Naphthol and few drops of conc. $\mathrm{H}_{2} \mathrm{SO}_{4}$ was added. At the junction of liquids, formation of violet ring indicates presence of carbohydrates.

Ruthenium red test- Accurately, $0.5 \mathrm{~mL}$ Ruthenium red reagent was added to the mucilage solution. Pink colour indicates presence of mucilage.

Iodine test- $1 \mathrm{~mL}$ of Iodine solution was added to the mucilage solution, appearance of reddish brown colour indicates presence of carbohydrates.

\section{Equipment and Process of Pelletization}

The extruder spheronizer equipped with a Screw type extruder and a cross hatch pattern spheronizer was used for the preparation of pellets containing Ciprofloxacin $\mathrm{HCl}$ (Extruder Spheronizer, UICELAB, Umang Pharmatech Pvt Ltd). Six different batches of formulation were prepared with different concentrations of polymer (Table 2). The contents of the formulation batches were mixed thoroughly and then damp mass was prepared with 15\% PVP K30 in isopropyl alcohol and water. The damp mass was then passed through extruder with $1.5 \mathrm{~mm}$ mesh aperture at $70 \mathrm{rpm}$ for $15 \mathrm{~min}$. The extrudates were then placed in spheronizer and it was then run at a speed of $700 \mathrm{rpm}$. The obtained pellets were then dried in hot air oven for $30 \mathrm{~min}$.

\section{Characterization of matrix pellets FTIR Study}

IR spectra were recorded for the pure drug, physical mixture of drug and excipient and optimized formulation. 
The sample mixed with IR grade $\mathrm{KBr}$ in the ratio of 1:100 and compressed using motorized pellet press at 10-12 tons pressure. The prepared pellets were then scanned over the range of $4000-400 \mathrm{~cm}^{-1}$ to get the IR spectra by using a FTIR spectrophotometer. The FTIR spectrum of physical mixtures was compared with reported spectra of pure drug and carrier, to confirm any changes occur or not in the principal peaks of spectra of plain drug and carrier.

\section{XRPD Study}

The crystallinity of pure ciprofloxacin $\mathrm{HCl}$ and optimized formulation was evaluated by XRPD. The patterns were recorded for pure drug and optimized formulation using an X- ray diffractometer ((Brucker Axs, 08 Advance). Samples were irradiated with $\mathrm{S}$ radiation and analysed between $2^{\circ} \mathrm{C}$ and $60^{\circ} \mathrm{C}$. The voltage and current used were $30 \mathrm{KV}$ and $30 \mathrm{~mA}$ respectively.

\section{Determination of Flow Properties}

Flow properties of different pellets formulation batches were determined which includes angle of repose, flow rate, Car's index and Hausner's Ratio.

\section{Determination of Friability}

The percent friability of pellets was determined using Roche Friabilator. Accurately, weighed $500 \mathrm{mg}$ of pellets $\left(\mathrm{W}_{1}\right)$ were placed in the chamber of a Roche Friabilator (Electrolab Friability tester, EF 2, Mumbai, India) and it was subjected to testing at $100 \mathrm{rpm}$. The pellets were weighed again after 100 revolutions. The percent friability was calculated by following equation,

$$
\text { Percent friability }=\frac{\mathrm{W} 1-\mathrm{W} 2}{\mathrm{~W} 1} * 100
$$

Where $\mathrm{W}_{1}=$ Initial weight of pellets, $\mathrm{W}_{2}=$ weight after 100 revolutions

\section{Determination of Roundness and Circularity}

The roundness and circularity of pellets was measured using a Motic DMWB2-223 digital microscope fitted with a 1/3 CCD Camera imaging accessory. Motic Images 2000 (1.3 Version) image analysis software was used for the measurements. The average diameter and different shape parameters such as roundness and circularity were determined from these images. ${ }^{24,25}$ The roundness and circularity values of the prepared pellets were determined by following equations,

$$
\begin{aligned}
& \text { Roundness }=\frac{0.9399 \mathrm{P}}{4 \pi \mathrm{A}} \\
& \text { Circularity }=\frac{4 \pi \mathrm{A}}{\mathrm{p}^{2}}
\end{aligned}
$$

Where, $\mathrm{P}$ is the perimeter of the pellet image and $\mathrm{A}$ isthe area determined by the total number of pixels within the feature. The factor 0.9399 corrects the perimeter for the effect of the corners produced by digitization of the image. A roundness value of 1 corresponds to the image of a perfect sphere.

\section{Surface Topography}

The surface morphology of pellets was analysed using a scanning electron microscopy (SEM) (S-4800, Type-II, Hitachi High Technologies Corp. Tokyo, Japan). The samples were mounted on aluminium stubs and then coated with palladium by using vacuum coater and images were captured. The examination was performed at an appropriated magnification (X-30, X-50, X-100,and $\mathrm{X}-1000)$ using scanning electron microscopy.

\section{Determination of Production Yield}

The production yield of manufactured pellets was determined using the weight of the final product after screening divided by the initial total weight of the formulation mixture (drug and other polymers) used for preparation of pellets. The percent production yields were calculated by the following equation,

Percent production yield $=\frac{\mathrm{Pw}}{\mathrm{Tw}} * 100$

Where $\mathrm{P}_{\mathrm{W}}=$ practical yield of pellets, $\mathrm{T}_{\mathrm{W}=}$ Theoretical yield of pellets

\section{Determination of Drug Content}

$100 \mathrm{mg}$ pellets were taken and triturated in mortar and pestle which was then dissolve in distilled water; volume was made up to $100 \mathrm{~mL}$ and sonicated for $10 \mathrm{~min}$, filtered through $0.45 \mu \mathrm{m}$ filter paper. $1.0 \mathrm{~mL}$ of filtrate was diluted up to $10 \mathrm{~mL}$ and the drug content was determined spectrophotometrically by measuring the absorbance at $270 \mathrm{~mm}$ (UV-1700, Shimadzu).

\section{Determination of Swelling Abilities of Pellets}

The swelling ability of each pellet to swell in media was determined by this test according to previously reported method. ${ }^{26,27,28}$ The accurately weighed $\left(\mathrm{W}_{1}\right)$ pellets were placed in plastic container containing $0.1 \mathrm{~N}$ HCL $(\mathrm{pH} 1.2)$ and allowed them to swell. The container was placed in Orbital shaking incubator (Remi Instruments Lmd-CSI-24). After relative time intervals the pellets were withdrawn from container, blotted with filter paper and weighed $\left(\mathrm{W}_{2}\right)$ again. The percentage of swelling was calculated using following equation.

$$
\text { Percent swelling }=\frac{\mathrm{W} 2-\mathrm{W} 1}{\mathrm{~W} 1} * 100
$$


Where $W_{1}=$ Weight of pellets before immersion into media $\mathrm{W}_{2}=\underset{\text { Weight }}{\text { media }}$
of pellets after immersion into

\section{Mucoadhesive Strength of Pellets}

The mucoadhesive strength of pellets was determined with in vitro wash-off test. ${ }^{29} \mathrm{In}$ this test a piece of intestinal mucosa of goat was $(2 \times 2 \mathrm{~cm})$ taken, mounted on glass slide. The slide was tied to the appropriate support. $50\left(\mathrm{~N}_{0}\right)$ pellets were spread on the piece of mucosa and it was hung to the arm of disintegration test apparatus. The apparatus was operated so that the glass slide with mucosal tissue could move in up and down movement in the test medium that is $0.1 \mathrm{~N} \mathrm{HCL}(\mathrm{pH} 1.2)$ maintained at $37 \pm 5^{\circ} \mathrm{C}$. The pellets were continuously observed for their adherence. After completion of $1 \mathrm{~h}$ pellets were washed with $0.1 \mathrm{~N} \mathrm{HCL}$ for $20 \mathrm{~min}$ and the pellets still adhering to the mucosa were counted $(\mathrm{N})$. The mucoadhesive strength of pellets in $0.1 \mathrm{~N} \mathrm{HCL}$ was determined using following equation,

$$
\mathrm{Na}=\frac{\mathrm{N}}{\mathrm{N} 0} * 100
$$

Where $\mathrm{N}_{2}=$ Mucoadhesion number, $\mathrm{N}=$ Pellets still adhering to the mucosa after 30 min, $\mathrm{N}_{0}=$ number of pellets spread on the mucosa before immersion in test media

\section{In vitro Drug Release Study}

$1000 \mathrm{mg}$ of pellets were taken to determine the drug release using USP paddle (Type II) apparatus 4 (TDT-08L plus, Electrolab, Mumabai, India). The paddle was then immersed in 0.1N HCL ( $\mathrm{pH} 1.2)$ because the main absorption window of the drug in stomach and maintained at $37 \pm 0.5^{\circ} \mathrm{C}$ at $100 \mathrm{rpm} .5 \mathrm{~mL}$ of sample was withdrawn after every $1 \mathrm{~h}$ up to $12 \mathrm{~h}$ and its drug release was measured spectrophotometrically at $270 \mathrm{~nm}$. Each in vitro release study was performed in triplicate. Experimental results are expressed as mean \pm S.D. The in vitro drug release data was fitted into zero order, first order, Higuchi, Korsmeyer-Peppas models.

\section{Stability Studies}

The optimized formulation was placed in environmental stability chamber for 90 days according to ICH guidelines Q1A (R2) to determine its stability at $40 \pm 2^{\circ} \mathrm{C}$ at $75 \pm 5 \% \mathrm{RH}$. The optimized formulation (NF1) was filled in glass vials, sealed and placed in stability chamber. The stability was characterised by percent friability, drug content and in vitro dissolution for the period of three months.
The experimental results are expressed as mean \pm S.D. Statistical evaluation of the data was done using ANOVA. The evaluation of data was used to assess the significance of differences. Statistically significant difference between the means of formulation batches was defined as $p<0.05$.

\section{RESULTS AND DISCUSSION}

Gastro retentive drug delivery system is an approach to prolong gastric residence time, there by targeting site-specific drug release in upper gastrointestinal tract (GIT). This system will have relatively less side effect and removes the need of repeated dosages and increase patient compliance. In the hypothesis, we have done the screening of various varieties of black gram seed which were available nearby region. From this screening we selected the species Vigna mungo for the study. For the extraction of polysaccharide simple maceration method of extraction was used. After extraction, the resulting polysaccharide material was screened for some pharmacognostic tests including Molisch's test, Ruthenium red test and Iodine test.

In the Molisch's test the violet ring at the junction of two liquids confirmed the presence of carbohydrates. In the Ruthenium red test the pinkish red colour to the particles of extracted material confirmed that mucilage was present in the extracted and isolated material. The presence of brown colour in Iodine test showed that, there was presence of carbohydrates in the extracted material. Based on test results, it is revealed that the extracted material was polysaccharide.

It was hypothesized to select the pellet over the tablet formulation because it has several advantages. Some of the advantages with respect to formulation are that there is no dose dumping; it can be divided in to desired dosage strength without process or formulation changes, when pellets containing the active ingredient are in the form of suspension, capsules, or disintegrating tablets, and they offer significant therapeutic advantages of pellets over tablets.

The drug excipient compatibility study was carried out to check whether there is any incompatibility between drug and the excipient. The release retarding excipient was taken in three concentrations such as low, medium, and high concentration. The optimization of formulation batches was done based on flow properties, friability, drug content, swelling ability and in vitro drug release study.

\section{FTIR Study}

The drug polymer interaction study was carried out by Fourier Transform Infrared Spectroscopy using $\mathrm{KBr}$ 


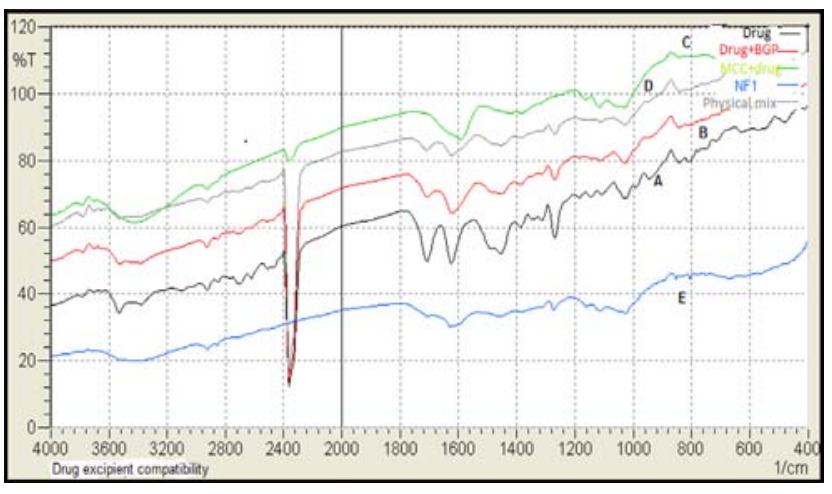

Figure 1: FTIR spectrum of pure drug, drug + black gram polysaccharide, MCC+drug, formulation (NF1) and physical mixture.

pellet method for pure drug, optimized formulation (NF1) and drug polymer combinations. The characteristic peaks of the drug (1400-1000, 3400-2400, 1725-1200, 1400-1200, 3000-2850, 3100-3500 $\mathrm{cm}^{-1}$ ) were also appeared in the spectra of all the drug- polymer combination. Optimized formulation (NF1) has showed no interaction between any of the polymer with drug or between both the polymers. Hence there were no signs of incompatibility between drug and the polymers (Figure 1; Table 1).

\section{XRPD Study}

The pure drug and optimized formulation (NF1) were studied to determine their physical state that is crystalline or amorphous. The pure drug showed typical crystalline peaks at $2 \theta=8.8^{\circ} \mathrm{C}, 19.1^{\circ} \mathrm{C}, 29.02^{\circ} \mathrm{C}$, and $26.23^{\circ} \mathrm{C}$ (Figure 2). The intensity of the peaks was observed to be decreased in the formulation blend. Due to change in peak intensity it is revealed that drug is converted from crystalline to amorphous form.

\section{Flow Properties of Matrix Pellets}

The flow properties of pellets formulations were determined which includes angle of repose, Hausnur's ratio, Carr's index and flow rate. (Table 3). The angle of repose of optimized batch was $25.07 \pm 2.20$ it indicated the good flow behaviour. The angle of repose of other batches was in the range of $21.50 \pm 0.37$ to $36.50 \pm 3.45$ which indicates that the angle of repose within the official limits. The Carr's index of NF1, NF2, NF3, SF1, SF2 formulation batches was less than 20 which indicates good flow ability. The measured flow rate was $0.87 \pm 0.03$ to $1.41 \pm 0.098 \mathrm{~g} / \mathrm{sec}$. The Hausnur's ratio of optimized batch was $1.13 \pm 0.10$ which indicates good flow ability. The Hausnur's ratio for the remaining formulations was in the range of $1.10 \pm 0.050$ to $1.24 \pm 0.022$ which was within the official limits.

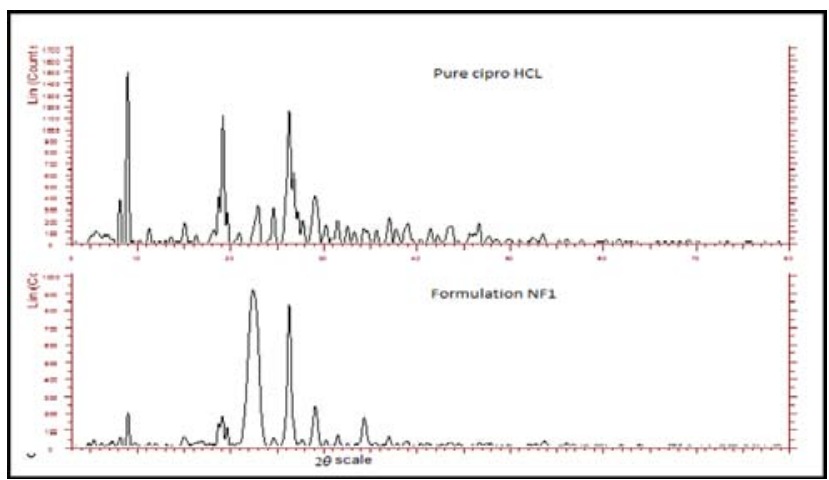

Figure 2: XRPD diffraction of pure drug and formulation blend (NF1) containing Ciprofloxacin HCL.

\section{Friability of matrix pellets}

The friability of matrix pellets was determined using Roche Friabilator. The percent friable amount gives the mechanical strength of pellets (Table 4). The percent friability of optimized formulation (NF1) was $0.60 \pm 0.03$ which indicates good mechanical strength and the percent friable amount of formulations NF3, SF1, SF2 was in the range of $0.40 \pm 0.067$ to $1.00 \pm 0.18$ which is within official limits. Batch NF2 and SF3 showed friability more than 1 which is not within the official limits. Lower the percent friable amount greater is its mechanical strength.

\section{Surface Topography}

SEM evaluation was important to know the surface topography, pellet size and shape. It was found that multiple unit matrix pellets has showed oral or spherical shape or nearly spherical with rigid surface (Figure 4).

\section{Determination of Production Yield and Drug Content}

The production yield and drug content for all the batches were determined. The production yield of optimized batch was $30.4 \%$ and for all the remaining batches it was found between 30-50\%. The drug content of optimized formulation (NF1) was found

\begin{tabular}{|c|c|c|c|}
\hline \multicolumn{4}{|c|}{ Table 1: Drug excipient compatibility through FTIR } \\
spectroscopy. \\
\hline $\begin{array}{c}\text { Ciprofloxacin } \\
\text { HCL }\end{array}$ & $\begin{array}{c}\text { Drug+ } \\
\text { Black Gram } \\
\text { Polysaccharide }\end{array}$ & $\begin{array}{c}\text { Drug+ (MCC) } \\
\text { Microcrystalline } \\
\text { Cellulose }\end{array}$ & $\begin{array}{c}\text { Physical } \\
\text { mixture }\end{array}$ \\
\hline 2924 & 1114.89 & 1425.44 & 1269 \\
\hline 1707 & 947.08 & 3419.90 & 1028.09 \\
\hline 1267.27 & 840.99 & 1116.82 & 839.06 \\
\hline 1028 & & 840.99 & 3520.21 \\
\hline 3527.92 & & & 1708.99 \\
\hline 1622.19 & & & 1624.12 \\
\hline
\end{tabular}


to be $97.79 \pm 0.60 \%$. The drug content of other formulation batches was in the range of $91.04 \pm 0.48$ to 96.15 $\pm 0.50 \%$ (Table 4).

\section{Determination of Roundness and Circularity}

The roundness and circularity of pellets was determined using Motic DMWB2-223 digital microscope fitted with a 1/3 CCD Camera imaging accessory. The optimized formulation (NF1) found nearly spherical and free flowing having circularity value of $0.9992 \pm 0.02$ and roundness value of $1.26 \pm 0.04$. Formulation batches NF2, NF3, SF1 and SF3 showed circularity and roundness values $0.9991 \pm 0.014$ to $0.9997 \pm 0.035$ and $1.18 \pm 0.032$ to $1.41 \pm 0.061$ respectively (Table 4 ). Based on sphericity results it is revealed the nearly spherical shape of pellets (Figure 3). Formulation SF2 formed some rod shaped particles having circularity value of
$0.875 \pm 0.061$ and roundness value of $1.97 \pm 0.019$ which might be due to lower concentration of binder solution.

\section{Swelling Ability of Matrix Pellets Containing Ciprofloxacin $\mathrm{HCl}$}

The swelling behaviour of the pellets indicated that the rate at which the pellets absorbed water from test media and swelled. The change in weight is a result of water uptake into the pellets and swelling were calculated for $60 \mathrm{~min}$. The swollen pellets absorbed water present in $0.1 \mathrm{~N} \mathrm{HCl}$ ( $\mathrm{pH}$ 1.2). The mechanism of swelling is that the polymers absorbs water and get swelled as water further penetrates into the formulation. The optimized formulation NF1 showed \% swelling of $72.65 \%$ in $0.1 \mathrm{~N}$ HCL ( $\mathrm{pH}$ 1.2). Formulation SF3 showed highest swelling up to $91.12 \%$ because of more absorption of water into the polymer. The other remaining formulations showed $\%$ swelling in the range of 76.14 to $89.6 .4 \%$.

\begin{tabular}{|c|c|c|c|c|c|c|}
\hline \multicolumn{6}{|c|}{ Table 2: Composition of Ciprofloxacin HCI matrix pellets in different batches. } \\
\hline Composition (mg) & NF1 & NF2 & NF3 & SF1 & SF2 & SF3 \\
\hline Ciprofloxacin HCl & 250 & 250 & 250 & 250 & 250 & 250 \\
\hline Ethyl cellulose & - & - & - & 200 & 300 & 400 \\
\hline Black gram Polysaccharide & 200 & 300 & 400 & - & - & - \\
\hline MCC & 400 & 300 & 200 & 400 & 300 & 200 \\
\hline PVP K30 & 150 & 150 & 150 & 150 & 150 & 150 \\
\hline $\begin{array}{c}\text { Total Weight / Hard Gelatin } \\
\text { Capsule }\end{array}$ & 1000 & 1000 & 1000 & 1000 & 1000 & 1000 \\
\hline
\end{tabular}

\begin{tabular}{|c|c|c|c|c|}
\hline \multicolumn{5}{|c|}{ Table 3: Flow properties of Ciprofloxacin HCI matrix pellets. } \\
\hline Batch No. & $\begin{array}{c}\text { Flow rate } \\
\text { (g/sec) }\end{array}$ & Angle of repose $\left.\mathbf{(}^{\circ}\right)$ & $\begin{array}{c}\text { Carr's index } \\
\text { (\%) }\end{array}$ & Hausnur's ratio \\
\hline NF1 & $1.01 \pm 0.010$ & $25.07 \pm 2.20$ & $16.83 \pm 1.53$ & $1.13 \pm 0.10$ \\
\hline NF2 & $1.1 \pm 0.079$ & $21.50 \pm 0.37$ & $11.84 \pm 1.53$ & $1.10 \pm 0.050$ \\
\hline NF3 & $1.41 \pm 0.098$ & $28.79 \pm 2.05$ & $9.23 \pm 0.71$ & $1.13 \pm 0.050$ \\
\hline SF1 & $1.068 \pm 0.10$ & $29.47 \pm 0.27$ & $15.75 \pm 0.89$ & $1.15 \pm 0.025$ \\
\hline SF2 & $0.87 \pm 0.03$ & $36.50 \pm 3.45$ & $19.40 \pm 0.57$ & $1.22 \pm 0.015$ \\
\hline SF3 & $1.17 \pm 0.010$ & $32.01 \pm 1.19$ & $21.79 \pm 0.22$ & $1.24 \pm 0.022$ \\
\hline
\end{tabular}

\begin{tabular}{|c|c|c|c|c|c|c|c|}
\hline \multicolumn{7}{|c|}{ Table 4: Physicochemical properties of matrix pellets. } \\
\hline $\begin{array}{c}\text { Batch } \\
\text { No. }\end{array}$ & $\begin{array}{c}\text { Friability } \\
(\%) \text { w/w }\end{array}$ & $\begin{array}{c}\text { Roundness } \\
\pm \text { S.D }\end{array}$ & Circularity \pm S.D & $\begin{array}{c}\text { Muco } \\
\text { adhesion } \\
(\%)\end{array}$ & $\begin{array}{c}\text { Drug content } \\
(\%)\end{array}$ & $\begin{array}{c}\text { Production } \\
\text { yield }(\%)\end{array}$ & $\begin{array}{c}\text { Description of } \\
\text { pellets }\end{array}$ \\
\hline NF1 & $0.60 \pm 0.03$ & $1.26 \pm 0.04$ & $0.9992 \pm 0.02$ & 72 & $97.79 \pm 0.60$ & $30.4 \%$ & Spheroids \\
\hline NF2 & $1.40 \pm 0.17$ & $1.34 \pm 0.078$ & $0.9994 \pm 0.07$ & 80 & $92.36 \pm 1.002$ & $42.29 \%$ & Spheroids \\
\hline NF3 & $1.0 \pm 0.18$ & $1.18 \pm 0.032$ & $0.9991 \pm 0.014$ & 86 & $95.58 \pm 1.88$ & $30.4 \%$ & Spheroids \\
\hline SF1 & $0.88 \pm 0.067$ & $1.41 \pm 0.061$ & $0.9997 \pm 0.035$ & 58 & $95.15 \pm 0.88$ & $40.1 \%$ & Spheroids \\
\hline SF2 & $0.40 \pm 0.063$ & $1.97 \pm 0.019$ & $0.875 \pm 0.061$ & 90 & $91.04 \pm 0.48$ & $42.6 \%$ & Rod shaped \\
\hline SF3 & $1.60 \pm 0.23$ & $1.39 \pm 0.053$ & $0.9995 \pm 0.027$ & 94 & $96.15 \pm 0.50$ & $35.6 \%$ & Spheroids \\
\hline
\end{tabular}




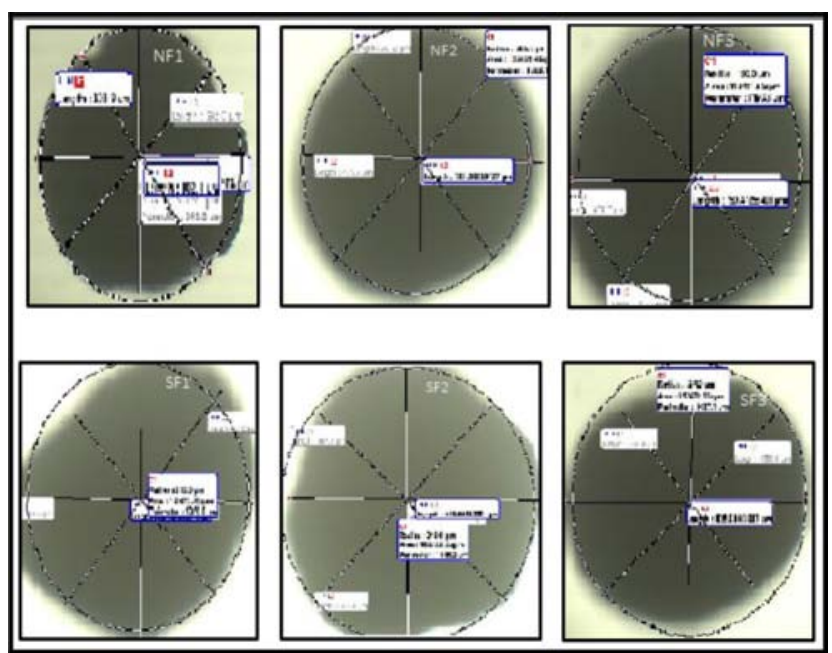

Figure 3: Photographic images of prepared different formulations.

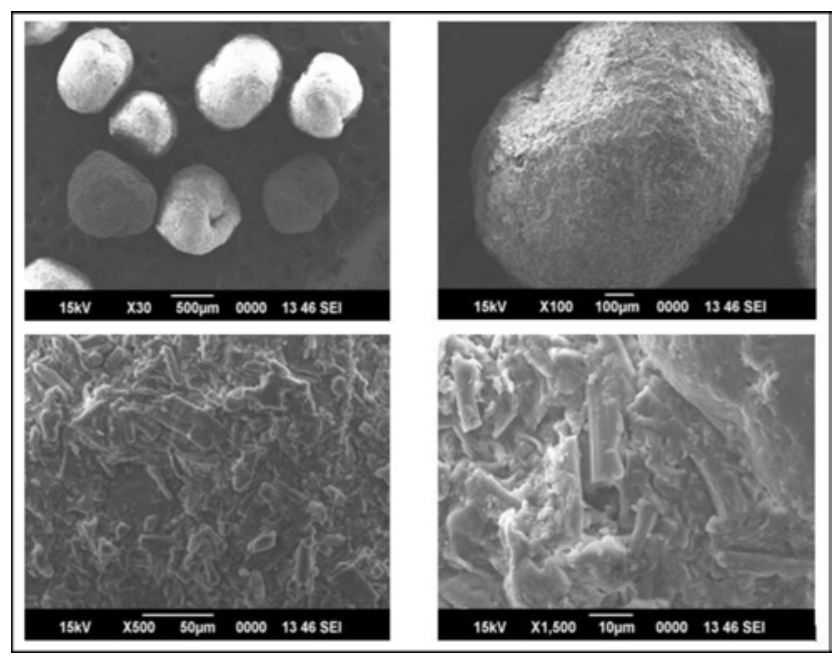

Figure 4: Photomicrographic images of optimized formulation NF1 at different magnifications.

\section{Mucoadhesive Strength of Matrix Pellets}

The matrix pellets exhibits good mucoadhesive strength in the wash-off test carried out on goat mucosal tissue. The optimized formulation NF1 showed good mucoadhesion of $72 \%$ while the formulation SF3 showed strong mucoadhesion of $94 \%$ in $0.1 \mathrm{~N}$ HCL which might be due to high concentration of polymer in the pellet formulation. Formulations NF2, NF3, SF1 and SF2 showed mucoadhesion in the range of $58-86 \%$ (Table 4).

\section{In vitro Drug Release Studies}

In-vitro dissolution studies of the pellet formulation was performed in $0.1 \mathrm{~N} \mathrm{HCL}$ for $12 \mathrm{~h}$. Optimized formulation (NF1) showed highest percent cumulative drug release of $96.08 \%$ up to $12 \mathrm{~h}$ (Figure 3) and showed sustained drug release which might be due to swelling of polymer. Formulations NF2, NF3, SF1, SF2 and SF3

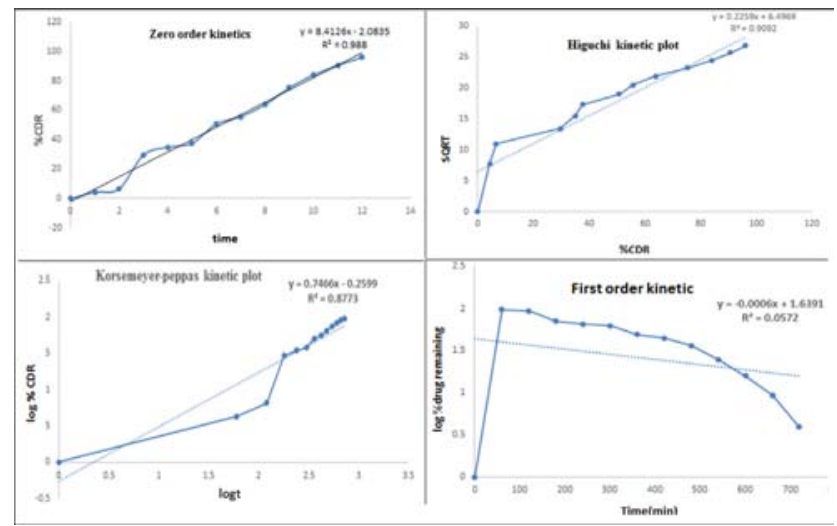

Figure 6: Drug release kinetics for optimized formulation (NF1).

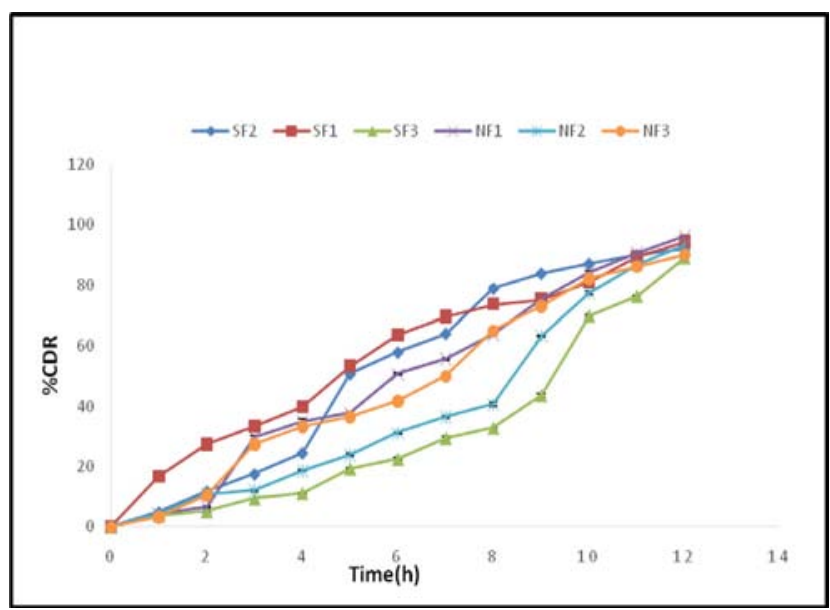

Figure 5: In-vitro drug release of matrix pellets formulations NF1, NF2, NF3, SF1, SF2, SF3 in 0.1N HCL (pH 1.2) medium.

showed sustained drug release up to $12 \mathrm{~h}$ as shown in Figure 5. The diffusional exponent (n) was calculated from the slope of the plots and regression coefficient $\left(\mathrm{R}^{2}\right)$ calculated. The optimized formulation (NF1) showed $\mathrm{n}$ values between 0.45 to 0.85 for spheres it indicated that the drug release by non-Fickian transport (Figure 6). The drug release from optimized formulation (NF1) followed zero order $\left(\mathrm{R}^{2}=0.988\right)$, Higuchi $\left(\mathrm{R}^{2}=0.9092\right)$, first order $\left(\mathrm{R}^{2}=0.0572\right)$ and KorsmeyerPeppas model $(\mathrm{R} 2=0.8773, \mathrm{n}=0.7466)$.

\section{Stability studies}

The optimized formulation (NF1) was subjected to stability studies according to ICH guidelines Q1A (R2) to determine its stability at $40 \pm 2^{\circ} \mathrm{C}$ at $75 \pm 5 \% \mathrm{RH}$ for the period of three months and percent friability, drug content, in vitro drug release were determined (Table 5). 
Table 5: Stability study of optimized formulation.

\begin{tabular}{|c|c|c|}
\hline Stability period & Parameter & Result \\
\hline \multirow{3}{*}{ First month } & Friability (\%) & 0.92 \\
\cline { 2 - 3 } & Drug content (\%) & 96.57 \\
\cline { 2 - 3 } & In vitro drug release (\%) & 96.73 \\
\hline \multirow{3}{*}{ Second month } & Friability (\%) & 0.69 \\
\cline { 2 - 3 } & Drug content (\%) & 96.08 \\
\cline { 2 - 3 } & In vitro drug release (\%) & 96.19 \\
\hline \multirow{3}{*}{ Third month } & Friability (\%) & 0.42 \\
\cline { 2 - 3 } & Drug content (\%) & 96.25 \\
\cline { 2 - 3 } & In vitro drug release (\%) & 96.05 \\
\hline
\end{tabular}

\section{CONCLUSION}

Black gram polysaccharide is naturally occurring excipient which can be used as drug release retardant in sustained release formulations. The multiple unit sustained release system was prepared by extrusion-spheronization technique using black gram polysaccharide and ethyl cellulose as release retarding polymer. The prepared pellets were characterised by flow properties, surface topography, $\mathrm{X}$-ray powder diffraction, percent production yield, drug content, mucoadhesive strength, percent swelling ability and in vitro drug release. The $\%$ production yield of optimized batch NF1 was $30.4 \%$ and the drug content was $97.79 \pm 0.60 \%$. The optimized formulation showed the sustained drug release up to 12 h i.e. $96.08 \%$. In conclusion, black gram polysaccharide can be effectively used as release retarding excipient in pellet formulations and the required drug release profile can be achieved.

\section{ACKNOWLEDGEMENT}

Authors are thankful to Aurobindo Pharmaceuticals, Hydrabad, India for providing gift sample of Ciprofloxacin $\mathrm{HCl}$. Authors would like to thank Dr. S. J. Surana Principal, RC Patel Institute of Pharmaceutical Education and Research, Shripur, Maharashtra, India for providing the necessary facilities to carry out this research work.

\section{CONFLCIT OF INTEREST}

The authors declare no conflict of interest.

\section{REFERENCES}

1. Rouge N, Buri P, Doelker E. Drug absorption sites in the gastrointestinal tract and dosage forms for site-specific delivery. Int. J. Pharm. 1996;136(1-2):117-39.

2. Dressman JB, Bass P, Ritschel WA, Friend DR, Rubinstein B, Ziv E. Gastrointestinal parameters that influence oral medications. J. Pharm Sci. 1993;82(9):857-72.
3. Vervaet C, Baert L, Remon, JP. Extrusion-spheronizationa literature review. Int. J. Pharm. 1995;116(2):131-46.

4. Muley S, Nandgude T, Poddar, S. Extrusion-spheronization a promising pelletization technique: In-depth review. A. J. Pharm. Sci. 2016;11(6):684-99.

5. LeBel M. Ciprofloxacin: Chemistry, mechanism of action, resistance, antimicrobial spectrum, pharmacokinetics, clinical trials, and adverse reactions. Pharmacotherapy: The J. H. Pharmacol. Drug Ther. 1996;8(1):3-30.

6. Varshosaz J, Tavakoli N, Roozbahani F. Formulation and in vitro characterization of ciprofloxacin floating and bio adhesive extended-release tablets. Drug Deliv. 2006;13(4):277-85.

7. Arza RA, Gonugunta CS, Veerareddy PR. Formulation and evaluation of swellable and floating gastro retentive ciprofloxacin $\mathrm{HCl}$ tablets. AAPS Pharm. Sci. Tech. 2009;10(1):220-6.

8. Bhat UR, Salimath PV, Tharanathan RN. A muscilaginous acidic polysaccharide from black gram (Phaseolus mungo): structure-function characteristics. Carbohydrate Res. 1987;161(1):161-6.

9. Harder S, Fuhr U, Beermann D, Staib AH. Ciprofloxacin absorption in different regions of the human gastrointestinal tract. Investigations with capsule. $\mathrm{Br}$. J. Clin. Pharmacol. 1990;30(1):35-9.

10. Pérez-Martínez JI, Morillo E, Maqueda C, Gines JM. Ethyl cellulose polymer microspheres for controlled release of norfluazon. Pest Management Science. 2001;57(8):688-94.

11. Li VH. Influence of drug properties and routes of drug administration on the design of sustained and controlled release systems. In Controlled Drug Delivery: Fundamentals and Applications, Second Edition. 1987:29(2):4-94.

12. Kulkarni GT, Gowthamarajan K, Dhobe RR, Yohanan F, Suresh B. Development of controlled release spheriods using natural polysaccharide as release modifier. Drug Deliv. 2005;12(4):201-6.

13. Nayak AK, Pal D, Santra K. Screening of polysaccharides from tamarind, fenugreek and jackfruit seeds as pharmaceutical excipients. Int. J. Bio. Macromol. 2015;79:756-60.

14. Reddy GC, Susheelamma NS, Tharanathan RN. Composition and properties of mucilaginous polysaccharide from native and fermented black gram flour. Carbohydrate Polym. 1990;12(2):189-202.

15. Sharma S, Pawar A. Low density multiparticulate system for pulsatile release of meloxicam. Int. J. Pharm. 2006;313(1-2):150-8.

16. Sriamornsak $P$, Thirawong $N$, Weerapol $Y$, Nunthanid J, Sungthongjeen $S$. Swelling and erosion of pectin matrix tablets and their impact on drug release behaviour. Eur. J. Pharm. Biopharm. 2007;67(1):211-9.

17. Chowdary KP, Rao YS. Design and in vitro and in vivo evaluation of mucoadhesive microcapsules of glipizide for oral controlled release: a technical note. AAPS Pharm. Sci. Tech. 2003;4(3):87-92.

18. Mortazavi SA. An in vitro assessment of mucus/mucoadhesive interactions. Int. J. Pharm. 1995;124(2):173-82.

19. Ige PP, Rajput P, Pardeshi C, Kawade R, Swami B, Mahajan H, et al. Development of pellets of nifedipine using HPMC K15 M and K-carrageenan as mucoadhesive sustained delivery system and in vitro evaluation. Ir. Polym. J. 2013;22(12):911-21

20. Tekade AR, Gattani SG. Dual cross-linked pulsatile beads for chronotherapy of asthma: development and evaluation. Drug Deliv. 2010;17(8):581-6.

21. Ige PP, Gattani SG. Development of low density microspheres of metformin $\mathrm{HCl}$ using ethyl cellulose and HPMC K4M: in vitro and in vivo characterization. Polym. Plastic Tech. Engin. 2012;51(15):1537-44.

22. Costa P, Lobo JM. Modeling and comparison of dissolution profiles. Eur. J. Pharm. Sci. 2001;13(2):123-33.

23. Shoaib MH, Tazeen J, Merchant HA, Yousuf RI. Evaluation of drug release kinetics from ibuprofen matrix tablets using HPMC. Pak J. Pharm. Sci. 2006;19(2):119-24.

24. Indian Pharmacopoeia, vol. II. Government of India, Ministry of Health and family Welfare, Delhi: Controller of Publications. 2014;1401.

25. Ige PP, Gattani SG. Design and in vitro and in vivo characterization of mucoadhesive matrix pellets of metformin $\mathrm{HCl}$ for oral controlled release: a technical note. Arch. Pharm. Res. 2012;35(3):487-98.

26. Blott SJ, Pye K. Particle shape: a review and new methods of characterization and classification. Sedimentology. 2008;55(1):31-63.

27. Podczeck F, Newton JM. A shape factor to characterize the quality of spheroids. J. Pharm. Pharmacol. 1994;46(2):82-5. 
Streubel A, Siepmann J, Bodmeier R. Gastroretentive drug delivery systems. Expert Opinion on Drug Deliv. 2006;3(2):217-33.

29. Veerareddy PR, Bajjuri S, Sanka K, Jukanti R, Bandari S, Ajmeru RK, et al. Formulation and evaluation of gastro retentive dosage form of ofloxacin. Stamford J. Pharm. Sci. 2011;4(1):9-18. UR. Structure of a galactoarabinan-rich pectic polysaccharide of native and fermented black gram (Phaseolus mungo). Carbohydrate Polym. 1994;23(2):121-7

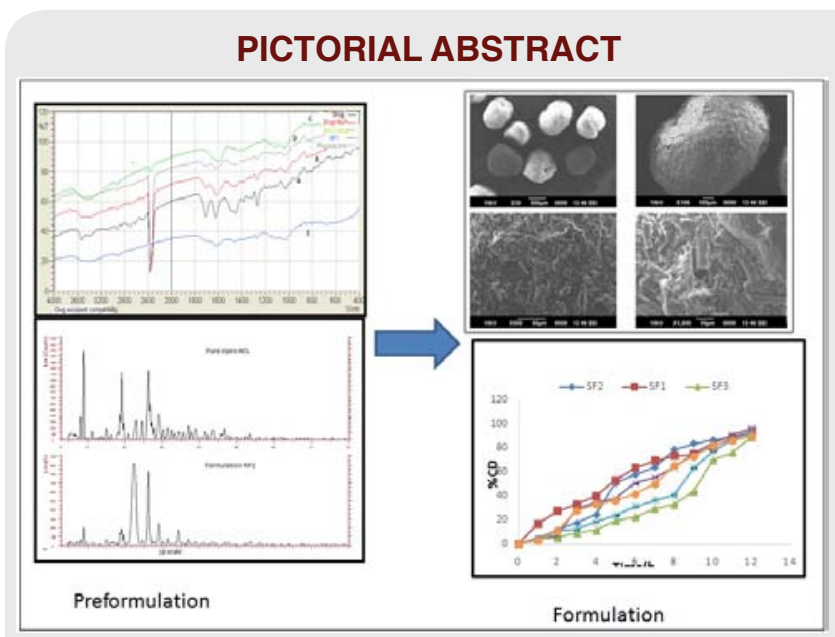

\section{SUMMARY}

- We prepared the matrix pellets by extrusion-spheronization technique.

- We performed mucoadhesion studies

- We successfully developed the sustained release matrix pellets of the highly soluble ciprofloxacin HCL using natural release retardant.

\section{About Author}

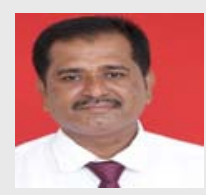

Dr. Ige Pradum Pundlikrao: Is an Associate Professor, at Department of Pharmaceutics, R C Patel Institute of Pharmaceutical Education and Research, Shirpur, Maharashtra. He has ten years of teaching, industry and research experience. He had been published thirty five research papers in various national/international journals of high impact factors. He is currently working on the topics of research such as expertise in vitro and ex vivo methods to assess single unit and multiple unit dosage form and designing and developing solubility enhancement methods for biopharmaceutical classification system-II drugs-nanoparticles. He is reviewer of various national/international journals. His major attainment is outstanding Reviewer Award by Elsevier Publications in 2016.

Cite this article: Pundlikrao IP, Pradip GP, Onkar SR. Use of Black Gram Polysaccharide Mucilage as Release Retardant in the Development of Sustained Release Matrix Pellets of Ciprofloxacin Hydrochloride. Indian $\mathrm{J}$ of Pharmaceutical Education and Research. 2018;52(3):389-97. 